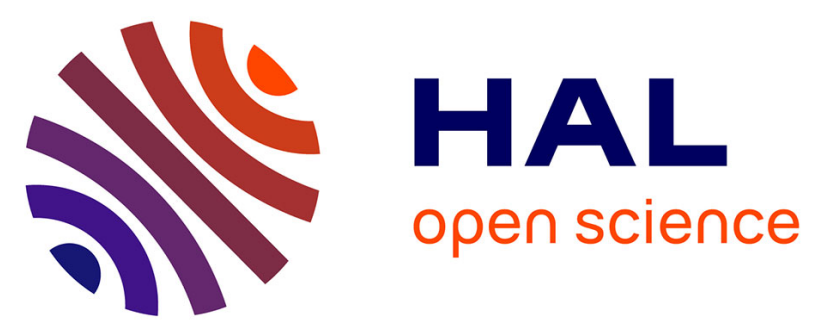

\title{
Effect of Antibiotic Therapy on Human Fecal Microbiota and the Relation to the Development of Clostridium difficile.
}

Marie-France de La Cochetière, T. Durand, Valérie Lalande, Jean-Claude Petit, Gilles Potel, Laurent Beaugerie

\section{To cite this version:}

Marie-France de La Cochetière, T. Durand, Valérie Lalande, Jean-Claude Petit, Gilles Potel, et al.. Effect of Antibiotic Therapy on Human Fecal Microbiota and the Relation to the Development of Clostridium difficile.. Microbial ecology, 2008, 56 (3), pp.395-402. 10.1007/s00248-007-9356-5 . inserm-00286509

\section{HAL Id: inserm-00286509 https://www.hal.inserm.fr/inserm-00286509}

Submitted on 22 Jan 2009

HAL is a multi-disciplinary open access archive for the deposit and dissemination of scientific research documents, whether they are published or not. The documents may come from teaching and research institutions in France or abroad, or from public or private research centers.
L'archive ouverte pluridisciplinaire HAL, est destinée au dépôt et à la diffusion de documents scientifiques de niveau recherche, publiés ou non, émanant des établissements d'enseignement et de recherche français ou étrangers, des laboratoires publics ou privés. 
1 Effect of antibiotic therapy on human fecal microbiota and the relation to the 2 development of Clostridium difficile.

4 De La Cochetière $M F^{* 1}$, Durand $\mathrm{T}^{2}$, Lalande $\mathrm{V}^{3}$, Petit $\mathrm{JC}^{3}$, Potel $\mathrm{G}^{2}$, Beaugerie $\mathrm{L}^{3}$.

6 INSERM, Université de Nantes, Nantes Atlantique Universités, Thérapeutiques Cliniques

7 et Expérimentales des Infections, EA 3826, UFR Médecine, rue G. Veil, Nantes, F-44000

8 France.

9 '2Université de Nantes, Nantes Atlantique Universités, Thérapeutiques Cliniques et 10 Expérimentales des Infections, EA 3826, UFR Médecine, rue G. Veil, Nantes, F-44000 11 France.

$12{ }^{3}$ Service de Gastro-entérologie et Nutrition, Hôpital Saint-Antoine, 184 rue du faubourg

13 Saint-Antoine, 75012 Paris Cedex, France.

Key words: Clostridium, Microbiota, TTGE, PLS regression.

22 Running head: Resident microbiota, Clostridium difficile.

*Corresponding author. Mailing address: UPRES EA 3826, UFR de Médecine, 1 rue Gaston mail: $\underline{\text { mfdlc@nantes.inserm.fr }}$ 
37 The gastrointestinal (GI) tract is a complex ecosystem. Recent studies have shown that the human fecal microbiota is composed of a consortium of microorganism. It is known that antibiotic treatment alters the microbiota, facilitating the proliferation of opportunists that may occupy ecological niches previously unavailable to them. It is therefore important to characterize resident microbiota to evaluate its latent ability to permit the development of pathogens such as Clostridium difficile. Using samples from 260 subjects enrolled in a previously published clinical study on antibiotic-associated diarrhea, we investigated the possible relationship between the fecal dominant resident microbiota and the subsequent development of $C$. difficile. We used molecular profiling of bacterial 16S rDNA coupled with PLS regression analysis. Fecal samples were collected on day $0\left(D_{0}\right)$ before antibiotic treatment and on day $14\left(D_{14}\right)$ after the beginning of the treatment. Fecal DNA was isolated and V6-to-V8 regions of the 16S rDNA were amplified by PCR with general primers and analyzed by Temporal Temperature Gradient gel Electrophoresis (TTGE). Main bacteria profiles were compared on the basis of similarity (Pearson correlation coefficient). The characteristics of the microbiota were determined using Partial Least Square (PLS) discriminant analysis model. Eighty seven TTGE profiles on $\mathrm{D}_{0}$ have been analyzed. The banding pattern was complex in all cases. The subsequent onset of $C$. difficile was not revealed by any clustering of TTGE profiles, but was explained up to $46 \%$ by the corresponding PLS model. Furthermore 6 zones out of the 438 dispatched from the TTGE profiles by the software, happened to be specific for the group of patients who acquired $C$. difficile. The first approach in the molecular phylogenetic analysis showed related sequences to uncultured clones. As for the 87 TTGE profiles on $\mathrm{D}_{14}$ no clustering could be found either, but the subsequent onset of $C$. difficile was explained up to $74.5 \%$ by the corresponding PLS model, thus corroborating the results

61 found on $\mathrm{D}_{0}$.

62 The non exhaustive data of the microbiota we found should be taken as the first step to assess

63 the hypothesis of permissive microbiota. The PLS model was used successfully to predict $C$. difficile development. We found that important criteria in terms of main bacteria could be markedly considered as predisposing factors for $C$. difficile development. Yet the resident microbiota in case of Antibiotic-Associated Diarrhea (AAD) has still to be analyzed. Further more, these findings suggest that strategies reinforcing the ability of the fecal microbiota to resist to modifications would be of clinical relevance. 


\section{Introduction}

71 The gastrointestinal (GI) tract is a complex ecosystem generated by the alliance of GI

72 epithelium, immune cells and resident microbiota. Experimental systems such as cell culture,

73 germ-free animal models and intestinal isografts have demonstrated that each member of the

74 GI ecosystem can follow a predetermined developmental pathway, even if isolated from the

75 other components of the ecosystem. However, the presence of all three components is

76 required for full physiological function [19]. Genetic or functional alterations of any one

77 component of this ecosystem can result in a broken alliance and subsequent GI pathology. In

78 this work, we will focus only on resident microbiota.

79 In both health and disease, the colonic microbiota plays an important role in several areas of

80 human physiology [15]. But this complex ecosystem is far from well known [29]. Culture-

81 independent 16S rDNA analyses have previously been used to examine the microbial

82 diversity of the human gut [25] and explorative multivariable analyses of 16S rDNA data to

83 study specific microbial communities [23].

84 In a previous study Beaugerie et al. clarified the role of C. difficile in Antibiotic-Associated

85 Diarrhea (AAD) in the community by prospectively studying a population of general-practice 86 patients by means of routine screening for both $C$. difficile and the $C$. difficile toxin B. $C$.

87 difficile was diagnosed by specific culture methods, and C. difficile toxin B was detected by

88 its cytopathic effect. As for diarrhoea, it was scored with the help of validated visual support.

89 Beaugerie's study was the first to demonstrate a high rate of acquisition (2,7\%) of toxin-

90 producing C. difficile during antimicrobial chemotherapy [2].

91 C. difficile produces two major toxins (toxins A and B). These are thought to be primarily

92 responsible for the virulence of the bacterium and the major contributors to the pathogenesis

93 of antibiotic-associated gastrointestinal disease [4]. Following most antibiotic treatment there

94 will be a point at which the impact on the normal gut microbiota depresses colonization

95 resistance to $C$. difficile. The composition of the pre-existing microbiota may have an

96 important role as well.

97 Therefore, in view of literature data [7, 16, 21, 26], we judged as particularly promising to

98 investigate the stool of the patients from Beaugerie's previous work. Thus the aim of the 99 present study was to test the hypothesis of predisposing factors slot in the resident microbiota.

100 We used a genetic fingerprinting method. The characteristics of the microbiota were 101 determined using Partial Least Square (PLS) discriminant analysis model. 


\section{Methods}

Patients. Our work is an explicative microbiological approach derived from a clinical study published elsewhere [2]. In short, 260 subjects enrolled in the latter study were adult outpatients living in the Paris area, who were prescribed a 5-10 day course of antimicrobial chemotherapy. Criteria for enrolment were prescription by a general practitioner of a 5-10 day course of antibiotics and age 18 years or older. Potential candidates were excluded if they were institutionalized subjects, had received antibiotic treatment during the previous 2 months, had been admitted to a hospital during the previous 6 months, had known human immunodeficiency virus infection, had any allergy, or had had a bout of diarrhea (more than 2 loose stools per day) the day before enrolment. All patients had given their written consent. Each patient was asked to store the last stool before the beginning of the antibiotherapy $\left(\mathrm{D}_{0}\right)$, and the stool 14 days after the beginning of the antibiotherapy $\left(\mathrm{D}_{14}\right)$, in double-thickness containers, and to keep them in a refrigerator or in a cool place until collection by the study monitor [2]. The antibiotics given were classified into 3 classes: class 1, amoxicillin/clavulanic acid; class 2, other beta-lactam agents; class 3, non beta-lactam agents. Among the 260 patients, 11 acquired $C$. difficile. Among the 249 remaining patients without C. difficile, 38 were chosen because they developed an AAD and paired with patients with no AAD according to age range (within 10-years) and class of antibiotic. Thus our study included a total of 87 patients. The 11 patients, 3 men and 8 women, with acquired C. difficile were from 28 to 73 years old, 5 had taken Pristinamycin, 3 of them Amoxicillin, and 3 of them Amoxicillin/clavulanic acid. Because a typical initial antibiotic dose has no effect on dominant fecal microbiota for at least 8 to 10 hours (data not shown) we considered the dominant microbiota profile on $\mathrm{D}_{0}$ as the profile at equilibrium for each patient.

DNA isolation, 16S rDNA amplification. Stool samples were collected in sterile tubes and immediately stored at $-80^{\circ} \mathrm{C}$ until analysis. Total DNA was isolated from fecal samples by using the bead beating method [28]: Immediately after collection, total DNA was extracted from a 125-mg fecal sample aliquot and purified as described by Godon et al.[10] The DNA concentration and its integrity (size, $>21 \mathrm{~kb}$ ) were estimated by agarose gel electrophoresis (with 1.5\% [wt/vol] agarose-1× Tris-borate-EDTA-1 ng of ethidium bromide $\mathrm{ml}^{-1}$ ). DNA was obtained from all samples $(0.23 \pm 0.1 \mu \mathrm{g} / \mu \mathrm{l})$. DNA isolated was subsequently used as a template to amplify the V6 to V8 regions of the bacterial 16S rDNA with primers U968-GC (5’ CGC CCG GGG CGC GGC CCG GGC GGG GCG GGG GCA CGG GGG GAA CGC GAA GAA CCT TAC) and L1401 (5’ GCG TGT GTA CAA GAC CC ). PCR was performed 
using Hot Star Taq DNA polymerase (Qiagen, Courtaboeuf, France). PCR mixtures of 50 $\mu \mathrm{L}$ contained: 1X PCR Buffer, $1.5 \mathrm{mM} \mathrm{Mg} \mathrm{Cl} 2,0.1 \mathrm{mM}$ of each dNTP, $0.5 \mu \mathrm{M}$ of primers U968GC and L1401, 2,5 U of Hot Star® Taq Polymerase, and approximately 1 ng of DNA. The samples were amplified in a Gene Amp PCR system 9700® (Perkin-Elmer, Nantes, France) by using the following program: $95^{\circ} \mathrm{C}$ for $15 \mathrm{~min}$; 30 cycles of $94^{\circ} \mathrm{C}$ for $1 \mathrm{~min}, 56^{\circ} \mathrm{C}$ for $1 \mathrm{~min}$, $72^{\circ} \mathrm{C}$ for $1.5 \mathrm{~min}$, and finally $72^{\circ} \mathrm{C}$ for $15 \mathrm{~min}$.

TTGE analysis of PCR amplicons Temporal Temperature Gradient gel Electrophoresis has been chosen (TTGE) as the culture independent method that allowed the main bacteria diversity to be compared among samples [27].

The Dcode universal mutation detection system (Bio-Rad, Paris, France) was used for sequence-specific separation of PCR products. Electrophoresis was performed through a 1 mm thick, 16 x16 cm polyacrylamide gel (8\% wt/vol acrylamide-bisacrylamide, $7 \mathrm{M}$ urea, 1.25x \% Tris-acetate EDTA (TAE), $55 \mu \mathrm{L}$ and $550 \mu \mathrm{l}$ of Temed and ammonium persulfate $10 \%$, respectively) using 7 liters of 1.25x TAE as electrophoresis buffer. Electrophoresis was run at a fixed voltage of $65 \mathrm{~V}$ for 969 min with an initial temperature of $66^{\circ} \mathrm{C}$ and a ramp rate of $0.2^{\circ} \mathrm{C} / \mathrm{h}$. For better resolution, voltage was fixed at $20 \mathrm{~V}$ for $5 \mathrm{~min}$ at the beginning of electrophoresis. Each well was loaded with 100-200 ng of amplified DNA plus an equal volume of $2 x$ gel loading dye $(0.05 \%$ bromophenol blue, $0.05 \%$ xylene cyanol, and $70 \%$ glycerol). As described earlier, a marker was used [7]. A temperature gradient from 66 to $70^{\circ} \mathrm{C}$ (ramp rate of $0.2^{\circ} \mathrm{C}$ /hour) was applied during electrophoresis. After completion of electrophoresis, the gel was stained in a $30 \mu \mathrm{g} / \mathrm{mL}$ Sybr Green solution (Sybr Green I, SigmaAldrich, St Quentin Fallavier, France), destained in 1.25x TAE, and analyzed using Quantity One ${ }^{\circledR}$ software of the Gel Doc 2000® system (Bio-Rad, Paris, France). Profiles were numerized and gray intensity recorded along a densitogram, each band giving rise to a peak.

TTGE gel analysis. TTGE profiles were compared by using Gel Compare II software (Applied-Maths, Saint-Martens -Latem, Belgium). The analysis took into account the number of bands, their position on the gel, and their intensity. This software translates each TTGE profile into a densitometric curve, drawing a peak for each band (the area under the peak being proportional to the intensity of the band). A threshold area value was used to remove small peaks on the densitometric curves (these can be detected purely as a result of the amount of DNA applied to the gel). A marker consisting of a PCR amplicon mix of seven 
170 cloned rDNAs from different bacterial species was used to normalize the profiles. During this

171 step the gel strips were stretched or shrunk so that the assigned bands on the reference 172 patterns matched their corresponding reference positions. Similarity coefficients (Pearson

173 correlation method) were then calculated for each pair of profiles, yielding a similarity matrix.

174 A dendrogram was constructed from this matrix by using a UPGMA algorithm (unweighted

175 pair group method using arithmetic averages) [14].

177 Sequence analysis. Each electrophoregram consisted of a curve in which grey intensity = $178 \mathrm{f}$ (migration distance). The curves were digitized from the migration distances ranging from 1 179 to 438 at steps of 1 interval, using the Gel Compare II software. Thus TTGE profiles were 180 dispatched into zones of interest from which dominant bands were selected and excised for 181 PCR and sequence analysis. Gel fragments were washed once in $200 \mu \mathrm{L}$ PCR water and kept 182 in $100 \mu \mathrm{L}$ PCR water overnight at $4^{\circ} \mathrm{C}$ for diffusion. Ribosomal DNA fragments were then 183 amplified from the dialyzate. The PCR reaction was as described above. The size and 184 concentration of the amplicons were evaluated on 1.5\% agarose gel containing EtBr. PCR products were sequenced by Genome Express (Meylan, France). Newly determined sequences were compared with those in GenBank by BlastN search (NCBI) and using the Ribosomal Database Project RDP II sequence-match facility (Michigan State University, USA) in order to ascertain their closest relatives.

Multiple linear regression analysis. PLS-regression (PLSR) is a method for relating two data matrices, $\mathrm{X}$ and $\mathrm{Y}$, by a linear multivariate model, but goes beyond traditional regression in that it models also the structure of X and Y. PLSR derives its usefulness from its ability to analyse data with many, noisy, collinear, and even incomplete variables in both $\mathrm{X}$ and $\mathrm{Y}$. PLSR has the desirable property that the precision of the model parameters improves with the increasing number of relevant variables and observations. In the present study $\mathrm{X}$ variables are the TTGE profiles of dominant resident microbiota and variable $Y$ is the presence or absence of C. difficile. Furthermore, this method allows the assumption that component $\mathrm{X}$ (dominant resident microbiota) is the component that is most relevant for predicting the variable $\mathrm{Y}$ (presence or absence of $C$. difficle) among others (sex, age, antibiotherapy). Relationships using PLS regression were established between dominant microbiota profiles and status of 201 patients, using the SIMCA software, version 9.0 (UMETRI, Umeå, 202 Sweden/www.umetrics.com). Each patient was given a code in which sex, stool sample, 203 status, antibiotics and age were stated. First the TTGE profiles of each patient on $\mathrm{D}_{0}$ and $\mathrm{D}_{14}$ 
204

205

206

207

208

209

210

211

212

213

214

215

216

217

218

219

220

221

222

223

224

225

226

227

228

229

230

231

232

233

234

235

236

were established. Then they were analysed using the Gel Compare software. Finally, PLS regression was used to investigate the relations between TTGE profiles of patients (X variables) and the presence or absence of $C$. difficile (variable Y). The number of useful PLS components is determined by cross-validation (SIMCA-P 9.0, 2001). The X-loadings and the Y-loadings are noted $\mathrm{w}^{*}$ and c, respectively. Groups of patients are presented as situated on a plane defined by PLS components. The explanatory performance of the model is evaluated using the $\mathrm{R}^{2}$ coefficient which corresponds to the part of the variance of variable $\mathrm{Y}$ explained by the $\mathrm{X}$ variables [18].

\section{Results}

Storage of fecal samples. In the previously published clinical study the interval between stool passage and laboratory processing was $26.9 \pm 8.3 \mathrm{~h}$ (range, 3 to $71 \mathrm{~h}$ ). In order to test the stability of the dominant fecal microbiota, fecal samples from 4 healthy volunteers were analysed in parallel. Those samples were kept simultaneously at $-80^{\circ} \mathrm{C}, 4^{\circ} \mathrm{C}$, and $20^{\circ} \mathrm{C}$ for 24 , 48 and 72 hours and then analyzed by Temporal Temperature Gradient gel Electrophoresis (TTGE). Results are expressed as percentages of similarity of TTGE profiles after storage under the indicated conditions in comparison with an aliquot of the same sample stored at $80^{\circ} \mathrm{C}$ (as the gold standard). After 24 hours, the percentages of similarity of TTGE profiles were of $88.6 \% \pm 5.2$ with storage at $4^{\circ} \mathrm{C}$ and $89.2 \% \pm 1.8$ with storage at $20^{\circ} \mathrm{C}$. After 48 hours they were $89.1 \% \pm 4$ and $87.5 \% \pm 1.9$ respectively and after 72 hours they were $82 \% \pm 7.4$ and $86 \% \pm 3.3$ respectively.

Intra-individual analysis. 174 TTGE profiles were analyzed, from $\mathrm{D}_{0}$ and $\mathrm{D}_{14}$ for each of the 87 patients studied. The banding pattern was complex in all cases. The dendrogram analysis showed that the TTGE profiles did not cluster according to presence or absence of $C$. difficile (UPGMA dendrogram not shown). Similarity percentages between $\mathrm{D}_{0}$ and $\mathrm{D}_{14}$ profiles for each of the 11 patients with acquired $C$. difficile, according to antibiotic classes, varied from i) 0\% (patient with AAD) and 90.8\% (patient without AAD) for amoxicillin - clavulanic acid, ii) $41 \%$ (patient with $\mathrm{AAD}$ ) and $71.3 \%$ (patient without $\mathrm{AAD}$ ) for other beta-lactam agents and iii) $60.4 \%$ (patient with AAD) and $84.4 \%$ (patient without AAD) for non beta-lactam antibiotics. 
237 Inter-individual analysis and PLS model: Relationships between the profiles included in the

238 PLS model and the results of "acquired $C$ difficile" are not easily established using a visual 239 observation of the profiles. We calculated a PLS model that linked the 87 TTGE profiles of 240 main bacteria (X variables) of patients and the subsequent onset of $C$. difficile (variable Y), 241 first on $D_{0}$ then on $D_{14}$. The cross-validation led to $R^{2}$ coefficient which denotes the 242 percentage of variation. On $\mathrm{D}_{0}$ the corresponding PLS model explained $46 \%$ of the variation 243 of the Y-matrix (development of C. difficile) (Fig. 1) and on $\mathrm{D}_{14} 74.5 \%$ (Fig. 2).

245 Sequence analysis: $\mathrm{D}_{0}$ TTGE profiles of the 11 patients with acquired $C$. difficile were 246 compared on the same gel (Fig. 3). The analysis of the 438 zones dispatched from TTGE 247 profiles by the software, showed that only 6 were specific for the group of patients with 248 acquired $C$. difficile. From those 6 zones of interest, 7 main bands have been selected taking 249 into account their optical density and distinctiveness. To gain insight into the phylogenetic 250 positions of those amplicon DNA, they were extracted from the gel and sequenced. The 251 sequences showed the highest similarity with sequences derived from different Clostridium 252 clusters of the low guanine+cytosine $(\mathrm{G}+\mathrm{C})$ gram positive species [5]. The average determined length of the DNA sequences was 500 bases, and phylogenetic analysis was based on 400 to 450 aligned homologous nucleotides (corresponding to positions 900 to 1400 in Escherichia coli 16S rDNA). Using the same approach, 2 zones of interest were identified at $\mathrm{D}_{14}$. Three bands were selected, extracted and sequenced. The characteristics of the 7 extracted sequences of D0 and of the 3 extracted sequences of D14 are shown in table 1 with the origin (fecal sample), sequence length (370-417), closest relative identification and percentage of identification. They all belong to Clostridiales order, Clostridiaceae, Eubacterium and Lachnospiraceae family.

\section{Discussion}

263 Our results support the concept of "permissive" microbiota. Using molecular profiling of 264 bacterial 16S rDNA coupled with PLS regression analysis, we found that important criteria in 265 terms of main bacteria of the fecal microbiota could be considered as predisposing factors for 266 C. difficle development. We did not intend to sequence all implicate bacteria species. The studied patients were adult out-patients living in the Paris area. We assumed that all were exposed equally to $C$. difficile from the environment. The PLS regression analysis gave a predictive ability of $46 \%$ for the resident microbiota of those patients who developed a 
271 following antibiotic treatment and corroborate a metaproteomic approach to link biological

272 functions to gene sequences. Furthermore, these findings suggest that strategies reinforcing

273 the ability of the resident microbiota to resist to modifications would be of clinical relevance.

274 Recent culture-independent molecular studies on healthy individuals have shown that the

275 intestinal microbiota is specific to the host and resistant to modification over time [27].

276 Although, the difficulty to identify the exact profile at equilibrium has already been discussed

277 [6], to take into account every patient's data including factors such as age, sex, clinical and/or

278 antibiotherapy, is rather difficult. It needs the help of an abstract model that uses

279 mathematical language to describe the behavior of the system by a set of variables and a set of

280 equations that establish relationships between the variables. PLS-regression is a particular

281 type of multivariate analysis which uses the two-block predictive PLS model to model the

282 relationship between two matrices. PLS-regression derives its usefulness from its ability to

283 analyze data with many, noisy, collinear, and even incomplete variables in both $\mathrm{X}$ and $\mathrm{Y}$.

284 PLS-regression has the advantageous property that the precision of the model parameters

285 improves with the increasing number of relevant variables and observations [8]. Thus we

286 chose PLS-regression for relating the resident microbiota to C. difficile development. PLS-

287 regression has been used in various disciplines such as chemistry, economics, medicine,

288 pharmaceutical science and microbiology [13, 18, 20]. The PLS-regression analysis of the

289 resident microbiota on $\mathrm{D}_{0}$ gives one significant component explaining $46 \%$ of the $\mathrm{Y}$-variance.

290 Our analysis shows that the data are clustered: The resident microbiota from patients with

291 later C. difficile development deviates from the main cluster. In addition PLS-regression

292 detected the variable that is highly linked to variable Y (acquired $C$. difficile) among a large

293 number of X variables (TTGE profile, age, sex and class of antibiotic) as applied to a large

294 number of observations. In our model the variable X (=TTGE profiles) had been detected

295 based on its significance, other $\mathrm{X}$ variables (age, sex and class of antibiotic) were not relevant

296 although a specific study with the different antibiotics would be warranted.

297 Thus the present report provides evidence for predisposing factors in resident microbiota.

298 Such scoring functions should aid in the identification of putative group of bacteria. Moreover

299 the model could be used to predict the inclusion of new patients by incorporating their TTGE

300 profiles into the model. Therefore, more information could be obtained from TTGE profiles

301 than those given by densitometric analyses. This model enabled the parameters affecting the

302 distribution of the microbiota to be examined. Nevertheless the molecular determinants and

303 host specificity have yet to be identified. 
304 Operational Taxonomic Unit or molecular species is defined as a set of sequences with less 305 than 2\% divergence in 400-450 aligned homologous nucleotides [25]. Thus most of the 306 sequences identified in this work were related to uncultured bacterium clones (99-98\%) from

307 Clostridiales order. Among the anaerobes the Clostridiales order are known to have a strong 308 catalytic activity.

309 The non exhaustive data of the microbiota we found show species only from Clostridiales 310 order, Clostridiaceae, Eubacterium and Lachnospiraceae family. This is not surprising since 311 novel or yet uncultured species are most often identified upon characterization of fecal 312 microbiota using cloned 16S rDNA genes librairies [11]. Recent culture-independent studies 313 have shown that approximately $70 \%$ of the dominant human gut microorganisms have not 314 been isolated and described [3].

315 Interestingly, after substractive densitometric analyses on $\mathrm{D}_{0}$ for the selected band 1 , we 316 found that it was common in 10 out of the 11 TTGE profiles of the selected patients and only 3172 out of the 76 others. Furthermore, among the 11 patients with acquired C. difficile, 5 318 developed AAD. They clustered separately from the 6 patients without AAD on $\mathrm{D}_{0}$ as well as 319 on $\mathrm{D}_{14}$, suggesting two different “sub-groups" of dominant microbiota. These results' 320 analyses are consistent with our hypothesis and merit confirmation. This will be tested with 321 patients who developed AAD.

322 Within $\mathrm{D}_{14}$ of antibiotherapy, the human fecal microbiota of patients was markedly 323 modulated. The alterations observed here (0\% patient with AAD and $90.8 \%$ patient without 324 AAD) in the structure of the microbiota upon amoxicillin - clavulanic acid treatment are 325 important enough to suggest two groups of patients. It had been determined that upon natural 326 oscillations of dominant fecal microbiota TTGE profiles would remain within $90 \%$ of 327 similarity with the equilibrium state over a period of two years in one volunteer [24]. Thus, 328 these observations suggest the occurrence of a specific resistant microbiota to amoxicillin 329 clavulanic acid and would warrant confirmation.

330 From the 5 patients with AAD one was found neither toxinogenic nor with toxin. Thus, in this 331 case, $C$. difficile could not be considered as cause of diarrhea, although a negative search for 332 toxin and/or toxinogenesis obviously does not constitute final proof for the absolute lack of $C$. 333 difficile spore in the microbiota.

334 The dendrogram analysis showed that the TTGE profiles did not cluster according to presence 335 or absence of $C$. difficile. But the PLS -regression model explained $46 \%$ of the variation of 336 the Y-matrix (development of C.difficile). This study assessed for each individual, the 337 significance of resident microbiota but did not intend to determine the composition of the 
338 dominant fecal microbiota in terms of bacterial genera or species. The new sequences found

339 in the genus Clostridium indicate the importance of this genus inside the microbiota and its

340 putative role in development of pathogens [7]. Molecular analyses of the bacterial microbiota

341 based on 16S rDNA have attracted attention as reliable methods for detection and

342 identification of bacterial species [1, 12, 17]. Techniques such as temporal temperature

343 gradient gel electrophoresis are attractive because they are conducive to high throughput

344 studies. TTGE successfully differentiates bacterial gene fragments of the same size but

345 different thermal stability. The uses and limits of TTGE in microbial ecology have already

346 been explored [7, 22]. The ability to apply statistical methods makes denaturing gel

347 electrophoresis fingerprinting techniques such as TTGE tools with great potential [7, 9]. Only

348 the dominant fraction of the fecal microbiota is assessed using the PCR-TTGE technique, as

349 applied here, with universal primers. The complexity of the profiles observed by TTGE will

350 represent the most prevalent species.

355 Acknowledgments: We express our gratitude to Dr. P. Tailliez and Pr. A. Andremont for 356 their helpful advice. Mr. T. Durand was supported by a grant from Biocodex Inc. 


\section{References}

358 1. Bartosch S, Fite A, Macfarlane GT, McMurdo ME (2004) Characterization of 359 bacterial communities in feces from healthy elderly volunteers and hospitalized 360 elderly patients by using real-time PCR and effects of antibiotic treatment on the fecal

2. Beaugerie L, Flahault A, Barbut F, Atlan P, Lalande V, Cousin P, Cadilhac M, Petit JC (2003) Antibiotic-associated diarrhoea and Clostridium difficile in the community. Aliment Pharmacol Ther 17:905-912

3. Blaut M, Collins MD, Welling GW, Dore J, van Loo J, de Vos W (2002) Molecular biological methods for studying the gut microbiota: the EU human gut flora project. Br J Nutr 87 Suppl 2:S203-211

4. Borriello SP (1998) Pathogenesis of Clostridium difficile infection. J Antimicrob Chemother 41 Suppl C:13-19

5. Collins MD, Lawson PA, Willems A, Cordoba JJ, Fernandez-Garayzabal J, Garcia P, Cai J, Hippe H, Farrow JA (1994) The phylogeny of the genus Clostridium: proposal of five new genera and eleven new species combinations. Int J Syst Bacteriol 44:812826

6. De La Cochetiere MF, Durand T, Lepage P, Bourreille A, Galmiche JP, Dore J (2005) Resilience of the dominant human fecal microbiota upon short-course antibiotic challenge. J Clin Microbiol 43:5588-5592

7. De La Cochetiere MF, Piloquet H, des Robert C, Darmaun D, Galmiche JP, Roze JC (2004) Early intestinal bacterial colonization and necrotizing enterocolitis in premature infants: the putative role of Clostridium. Pediatr Res 56:366-370

8. Eriksson L, Antti H, Gottfries J, Holmes E, Johansson E, Lindgren F, Long I, Lundstedt T, Trygg J, Wold S (2004) Using chemometrics for navigating in the large data sets of genomics, proteomics, and metabonomics (gpm). Anal Bioanal Chem 380:419-429

9. Fromin N, Hamelin J, Tarnawski S, Roesti D, Jourdain-Miserez K, Forestier N, Teyssier-Cuvelle S, Gillet F, Aragno M, Rossi P (2002) Statistical analysis of denaturing gel electrophoresis (DGE) fingerprinting patterns. Environ Microbiol 4:634-643

10. Godon JJ, Zumstein E, Dabert P, Habouzit F, Moletta R (1997) Molecular microbial diversity of an anaerobic digestor as determined by small-subunit rDNA sequence analysis. Appl Environ Microbiol 63:2802-2813

11. Hayashi H, Sakamoto M, Benno Y (2002) Fecal microbial diversity in a strict vegetarian as determined by molecular analysis and cultivation. Microbiol Immunol 46:819-831

12. Hayashi H, Sakamoto M, Benno Y (2002) Phylogenetic analysis of the human gut microbiota using 16S rDNA clone libraries and strictly anaerobic culture-based methods. Microbiol Immunol 46:535-548

13. Huang XY, Chen JW, Gao LN, Ding GH, Zhao YZ, Schramm KW (2004) Data evaluations and quantitative predictive models for vapor pressures of polycyclic aromatic hydrocarbons at different temperatures. SAR QSAR Environ Res 15:115-125

14. Lepage P. PS, M Sutren, MF De La Cochetiere, J Raymond, P Marteau and J Dore (2005) Biodiversity of the mucosa-associated microbiota is stable along the distal digestive tract in healthy individuals and patients with IBD. IBD

15. Macfarlane GT, Macfarlane S (1997) Human colonic microbiota: ecology, physiology and metabolic potential of intestinal bacteria. Scand J Gastroenterol Suppl 222:3-9 
16. Marteau P, Lepage P, Mangin I, Suau A, Dore J, Pochart P, Seksik P (2004) Review article: gut flora and inflammatory bowel disease. Aliment Pharmacol Ther 20 Suppl 4:18-23

17. Matsuki T, Watanabe K, Fujimoto J, Takada T, Tanaka R (2004) Use of 16S rRNA gene-targeted group-specific primers for real-time PCR analysis of predominant bacteria in human feces. Appl Environ Microbiol 70:7220-7228

18. Matte-Tailliez O, Lepage E, Tenenhaus M, Tailliez P (2002) Use of predictive modeling for Propionibacterium strain classification. Syst Appl Microbiol 25:386-395

19. McCracken VJ, Lorenz RG (2001) The gastrointestinal ecosystem: a precarious alliance among epithelium, immunity and microbiota. Cell Microbiol 3:1-11

20. Morel E, Santamaria K, Perrier M, Guiot SR, Tartakovsky B (2004) Appliquation of multi-wavelength fluorometry for on-line monitoring of an anaerobic digestion process. Water Res 38:3287-3296

21. Odenbreit S, Puls J, Sedlmaier B, Gerland E, Fischer W, Haas R (2000) Translocation of Helicobacter pylori CagA into gastric epithelial cells by type IV secretion. Science 287:1497-1500

22. Ogier JC, Son O, Gruss A, Tailliez P, Delacroix-Buchet A (2002) Identification of the bacterial microflora in dairy products by temporal temperature gradient gel electrophoresis. Appl Environ Microbiol 68:3691-3701

23. Rudi K, Maugesten T, Hannevik SE, Nissen H (2004) Explorative multivariate analyses of 16S rRNA gene data from microbial communities in modifiedatmosphere-packed salmon and coalfish. Appl Environ Microbiol 70:5010-5018

24. Seksik P, Rigottier-Gois L, Gramet G, Sutren M, Pochart P, Marteau P, Jian R, Dore J (2003) Alterations of the dominant faecal bacterial groups in patients with Crohn's disease of the colon. Gut 52:237-242

25. Suau A, Bonnet R, Sutren M, Godon JJ, Gibson GR, Collins MD, Dore J (1999) Direct analysis of genes encoding 16S rRNA from complex communities reveals many novel molecular species within the human gut. Appl Environ Microbiol 65:4799-4807

26. Tannock GW (2002) Exploring the relationships between intestinal microflora and inflammatory conditions of the human bowel and spine. Antonie Van Leeuwenhoek 81:529-535

27. Zoetendal EG, Akkermans AD, De Vos WM (1998) Temperature gradient gel electrophoresis analysis of 16S rRNA from human fecal samples reveals stable and host-specific communities of active bacteria. Appl Environ Microbiol 64:3854-3859

28. Zoetendal EG, Ben-Amor K, Akkermans AD, Abee T, de Vos WM (2001) DNA isolation protocols affect the detection limit of PCR approaches of bacteria in samples from the human gastrointestinal tract. Syst Appl Microbiol 24:405-410

29. Zoetendal EG, Cheng B, Koike S, Mackie RI (2004) Molecular microbial ecology of the gastrointestinal tract: from phylogeny to function. Curr Issues Intest Microbiol $5: 31-47$ 
Table 1: Data of the sequences: origin, sequence length, closest relative identification

\begin{tabular}{|c|c|c|c|c|c|c|}
\hline $\begin{array}{c}\mathrm{N}^{\circ} \\
\text { extract. } \\
\text { bande }\end{array}$ & $\begin{array}{l}\text { Accesion } \\
\text { Number }\end{array}$ & Origin & $\begin{array}{l}\text { Sequence } \\
\text { length } \\
\text { (letter) }\end{array}$ & $\begin{array}{l}\text { Closest } \\
\text { relative }\end{array}$ & $\begin{array}{l}\text { Phylum/class of the } \\
\text { closest relative }\end{array}$ & $\begin{array}{l}\% \\
\text { Iden } \\
\text { tity }\end{array}$ \\
\hline 1 & EU196222 & $\begin{array}{l}\text { Fecal } \\
\text { sample } \\
\text { Individual }\end{array}$ & 395 & $\begin{array}{l}\text { Uncultured } \\
\text { bacterium }\end{array}$ & $\begin{array}{l}\text { Genus Ruminococcus, } \\
\text { (DQ802748) }\end{array}$ & 99 \\
\hline 2 & EU196223 & $\begin{array}{l}\text { Fecal } \\
\text { sample } \\
\text { Individual }\end{array}$ & 394 & $\begin{array}{l}\text { Uncultured } \\
\text { bacterium }\end{array}$ & $\begin{array}{l}\text { Unclassified_Clostridiale } \\
\text { s (AY984391) }\end{array}$ & 99 \\
\hline 3 & EU196224 & $\begin{array}{l}\text { Fecal } \\
\text { sample } \\
\text { Individual }\end{array}$ & 395 & Clostridium & $\begin{array}{ll}\text { Clostridium } & \text { sp. } \\
\text { (AJ582080) } & \end{array}$ & 98 \\
\hline 4 & EU196225 & $\begin{array}{l}\text { Fecal } \\
\text { sample } \\
\text { Individual } \\
\end{array}$ & 391 & $\begin{array}{l}\text { Uncultured } \\
\text { bacterium }\end{array}$ & $\begin{array}{l}\text { Genus Ruminococcus } \\
\text { (DQ905852) }\end{array}$ & 99 \\
\hline 5 & EU196226 & $\begin{array}{l}\text { Fecal } \\
\text { sample } \\
\text { Individual }\end{array}$ & 370 & $\begin{array}{l}\text { Uncultured } \\
\text { bacterium }\end{array}$ & $\begin{array}{l}\text { Genus Ruminococcus } \\
\text { (AM277309) }\end{array}$ & 99 \\
\hline 6 & EU196227 & $\begin{array}{l}\text { Fecal } \\
\text { sample } \\
\text { Individual }\end{array}$ & 386 & $\begin{array}{l}\text { Uncultured } \\
\text { bacterium }\end{array}$ & $\begin{array}{l}\text { Genus Dorea/ family } \\
\text { Clostridiaceae } \\
\text { (DQ802652) }\end{array}$ & 99 \\
\hline 7 & EU196228 & $\begin{array}{l}\text { Fecal } \\
\text { sample } \\
\text { Individual }\end{array}$ & 394 & $\begin{array}{l}\text { Uncultured } \\
\text { bacterium }\end{array}$ & $\begin{array}{l}\text { Genus Eubacterium } \\
\text { (AM275432) }\end{array}$ & 91 \\
\hline 8 & EU196229 & $\begin{array}{l}\text { Fecal } \\
\text { sample } \\
\text { Individual }\end{array}$ & 405 & $\begin{array}{l}\text { Uncultured } \\
\text { bacterium }\end{array}$ & $\begin{array}{l}\text { unclassified_Lachnospir } \\
\text { aceae } \\
\text { (AY235653) }\end{array}$ & 100 \\
\hline 9 & EU196230 & $\begin{array}{l}\text { Fecal } \\
\text { sample } \\
\text { Individual } \\
\end{array}$ & 417 & $\begin{array}{l}\text { Uncultured } \\
\text { bacterium }\end{array}$ & Genus Ruminococcus & \\
\hline 10 & EU196231 & $\begin{array}{l}\text { Fecal } \\
\text { sample } \\
\text { Individual }\end{array}$ & 389 & $\begin{array}{l}\text { Uncultured } \\
\text { bacterium }\end{array}$ & \begin{tabular}{l}
\multicolumn{3}{l}{ Genus Ruminococcus } \\
Uncultured \\
(EF071261)
\end{tabular} & 94 \\
\hline
\end{tabular}




\section{Legends to figures}

460 Figure 1: 3D representation of the PLS regression model showing relationship between

461 TTGE profiles of dominant species before any antibiotic treatment $\left(\mathrm{D}_{0}\right)$ and the subsequent 462 onset of $C$. difficile. The corresponding model explained 46\% of the estimated modification. 463 Positions of the $\mathrm{D}_{0}$ TTGE profiles of patients who acquired $C$. difficile are indicated in this 464 3D representation, by rectangles, position of the $\mathrm{D}_{0}$ TTGE profiles of others are indicated by 465 triangles.

467 Figure 2: 3 3 representation of the PLS regression model showing relationship between 468 TTGE profiles of dominant species 14 days after the antibiotic treatment $\left(\mathrm{D}_{14}\right)$ and the 469 subsequent onset of $C$. difficile. The corresponding model explained $74.5 \%$ of the estimated 470 modification. Positions of the $\mathrm{D}_{14}$ TTGE profiles of patients who acquired C. difficile are 471 indicated in this $3 \mathrm{D}$ representation, by rectangles, position of the $\mathrm{D}_{14}$ TTGE profiles of others 472 are indicated by triangles.

474 Figure 3: Temporal temperature gradient gel electrophoresis of 16S rDNA amplicons 475 (amplified with universal primers for the V6-V8 region of the gene) of fecal samples obtained 476 at day 0 , before any antibiotherapy, from the 11 patients who acquired a C. difficile after the 477 antibiotherapy.

479 Figure 4: $\quad$ Example of Temporal temperature gradient gel electrophoresis of 16S rDNA 480 amplicons (amplified with universal primers for the V6-V8 region of the gene) of fecal 481 samples from patients 6 and 9, who acquired C. difficile after the antibiotherapy, at Day 0 and 482 Day 14. 
493 Figure 1:

494

495

496

497

498

499

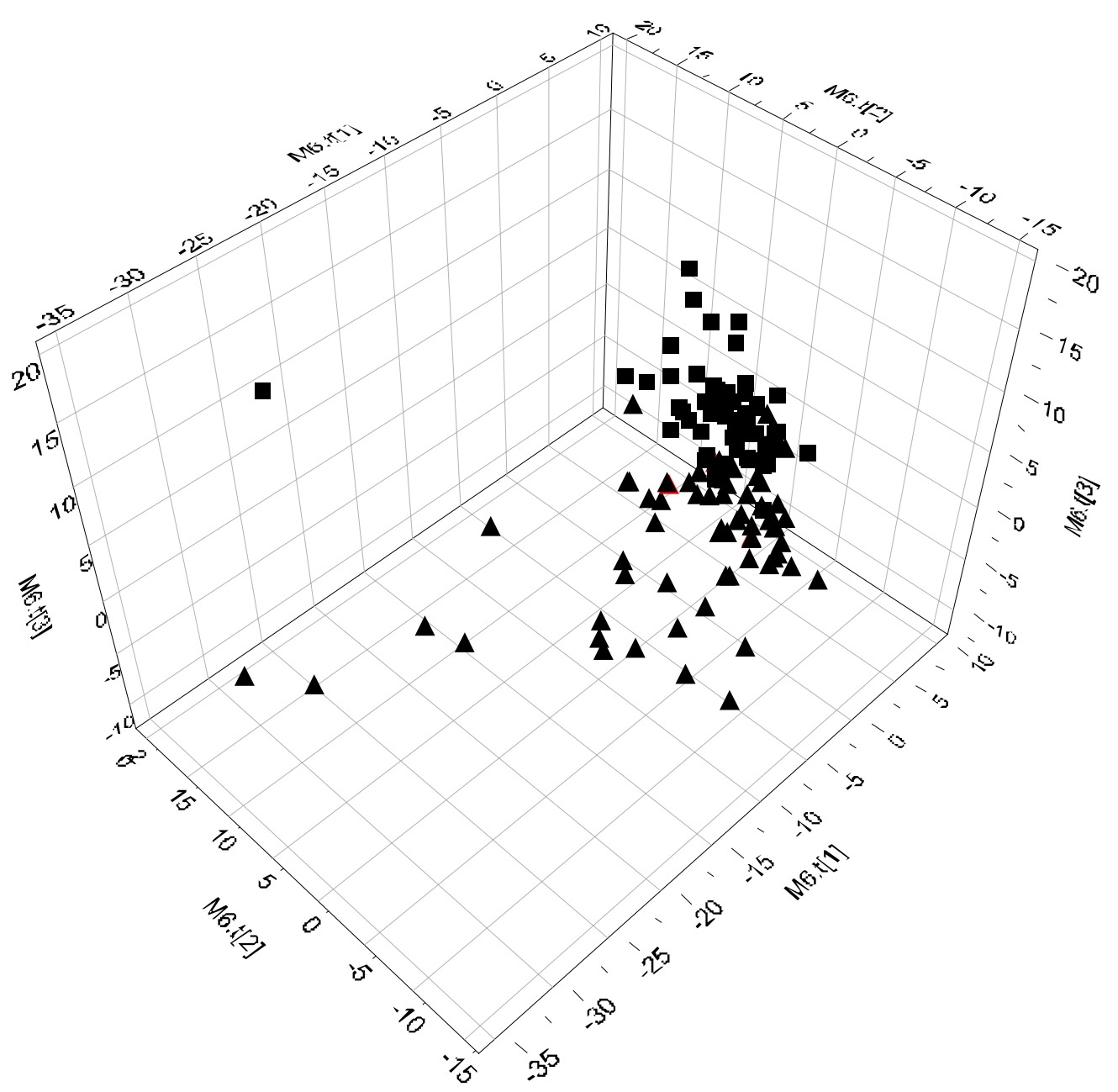

520

521

522

523

524

525

526 
527 Figure 2:

528

529

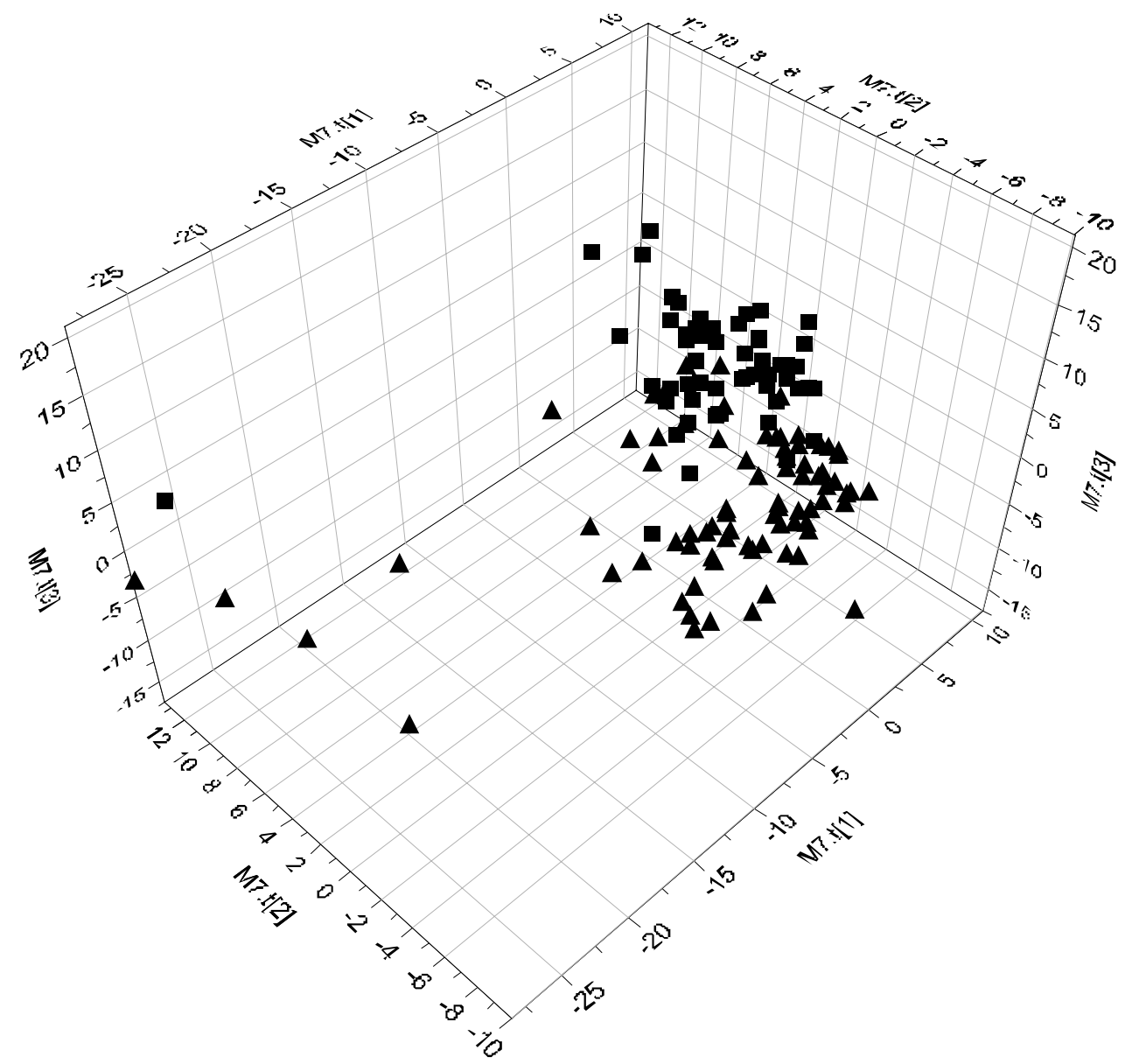


561 Figure 3:

562

563

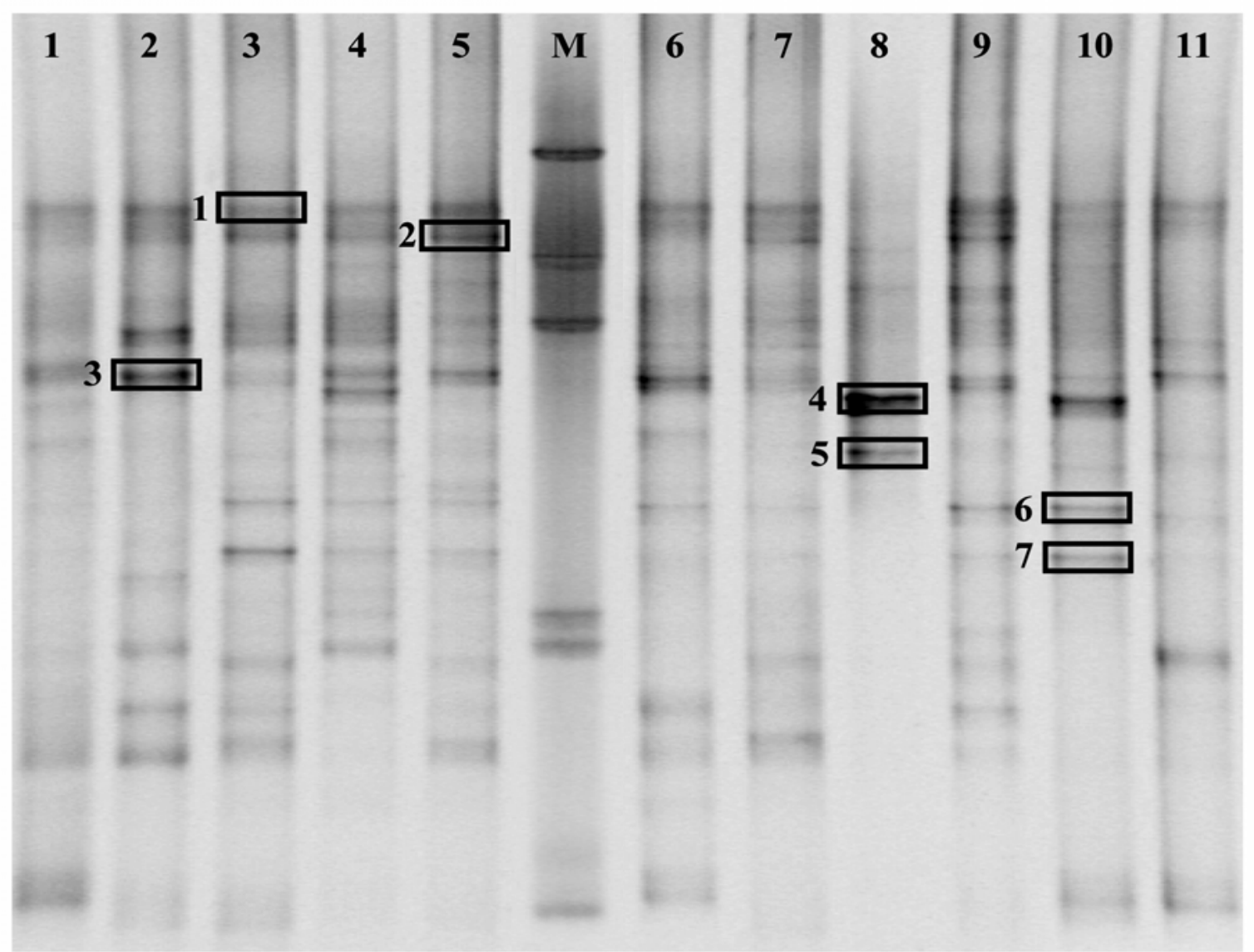

564

565 
566

567

$\begin{array}{llll}\text { D14 D0 D14 D0 } & \text { Clostridium species }\end{array}$

568 